\title{
TGF $\beta$ inhibition enhances the generation of hematopoietic progenitors from human ES cell-derived hemogenic endothelial cells using a stepwise strategy
}

\author{
Chengyan Wang ${ }^{1, *}$, Xuming Tang ${ }^{1, *}$, Xiaomeng Sun ${ }^{1,2, *}$, Zhenchuan Miao ${ }^{1}$, Yaxin $\mathrm{Lv}^{1}$, Yanlei Yang ${ }^{1}$, \\ Huidan Zhang ${ }^{1}$, Pengbo Zhang ${ }^{1}$, Yang Liu ${ }^{1,2}$, Liying Du ${ }^{1}$, Yang Gao ${ }^{1}$, Ming Yin $^{1}$, Mingxiao Ding ${ }^{1}$, Hongkui Deng ${ }^{1,2}$ \\ ${ }^{I}$ Department of Cell Biology, The MOE Key Laboratory of Cell Proliferation and Differentiation, College of Life Sciences, Peking \\ University, Beijing 100871, China; ${ }^{2}$ Laboratory of Chemical Genomics, Shenzhen Graduate School of Peking University, The Uni- \\ versity Town, Shenzhen 518055, China
}

Embryonic hematopoiesis is a complex process. Elucidating the mechanism regulating hematopoietic differentiation from pluripotent stem cells would allow us to establish a strategy to efficiently generate hematopoietic cells. However, the mechanism governing the generation of hematopoietic progenitors from human embryonic stem cells (hESCs) remains unknown. Here, on the basis of the emergence of $\mathrm{CD} \mathrm{C3}^{+}$hematopoietic cells from hemogenic endothelial (HE) cells, we demonstrated that VEGF was essential and sufficient, and that bFGF was synergistic with VEGF to specify the $\mathrm{HE}$ cells and the subsequent transition into $\mathrm{CD}^{+} 3^{+}$hematopoietic cells. Significantly, we identified TGF $\beta$ as a novel signal to regulate hematopoietic development, as the TGF $\beta$ inhibitor SB 431542 significantly promoted the transition from $\mathrm{HE}$ cells into $\mathrm{CD}^{+} 3^{+}$hematopoietic progenitor cells (HPCs) during hESC differentiation. By defining these critical signaling factors during hematopoietic differentiation, we can efficiently generate HPCs from hESCs. Our strategy could offer an in vitro model to study early human hematopoietic development.

Keywords: embryonic stem cells; hematopoietic progenitors; SB431542

Cell Research (2012) 22:194-207. doi:10.1038/cr.2011.138; published online 23 August 2011

\section{Introduction}

Human embryonic stem cells (hESCs) and induced pluripotent stem (iPS) cells have unlimited proliferative capacity and are able to differentiate into multiple lineages, offering the promise of cell-replacement therapies for blood diseases. Previous studies have demonstrated that hESCs can differentiate into hematopoietic progenitor cells/stem cells (HPCs/HSCs) through the formation of embryoid bodies (EBs), or co-culture with hematopoiesis-supporting stromal cells, such as the OP9, S17 and AM20.1B4 cell lines [1-5]. Recent studies have shown that iPS cells can also differentiate into

\footnotetext{
*These three authors contributed equally to this work. Correspondence: Hongkui Deng

Fax: +86-10-6275-6954

E-mail: hongkui_deng@pku.edu.cn

Received 13 February 2011; revised 4 May 2011; accepted 13 June 2011; published online 23 August 2011
}

HPCs $[6,7]$. However, these differentiation approaches have considerable drawbacks, such as being uncommitted and undefined, making them not optimal for studying the mechanisms of human hematopoietic development.

The establishment of a defined and stepwise strategy for generating hematopoietic cells from embryonic stem cells is valuable for the study of early hematopoietic development, and the EB strategy has been reported in the hematopoietic differentiation of mouse embryonic stem cells (mESCs) [8-10]. In these systems, hematopoietic differentiation was generally divided into steps containing BRACHYURY ${ }^{+}$embryonic primitive streak (PS), $\mathrm{KDR}^{+} / \mathrm{Flk}^{+}$mesoderm and $\mathrm{CD} 41^{+}$hematopoietic progenitor generation. Cytokines essential for the hematopoietic development were added to promote differentiation. A recent study also described a method to differentiate hematopoietic cells from hESCs in a defined medium [11]. However, hematopoietic cytokines were administered throughout the entire process of differen- 
tiation, thus their precise effects on each developmental stage were less defined.

A reliable strategy to generate $\mathrm{HSCs} / \mathrm{HPCs}$ from hESCs would be to recapitulate hematopoietic ontogeny based on a thorough understanding of the key signaling pathways controlling each developmental stage. Embryonic hematopoietic development is a complex process that involves a series of lineage specification precursors occurring at multiple anatomical sites within the embryo $[12,13]$. The first distinguishable embryogenic stage is the formation of the PS containing posterior and anterior parts that subsequently develop into the mesoderm and endoderm, respectively $[14,15]$. A subset of the early mesoderm in the posterior PS has the developmental potential to generate primitive and definitive hematopoietic cells [16]. These hematopoiesis-potential mesoderm cells initiate primitive hematopoiesis after migrating to the yolk sac and can subsequently produce definitive hematopoietic cells $[17,18]$. The first definitive HSCs arise at the ventral wall of the dorsal aorta in the aorta-gonadmesonephros (AGM) region $[19,20]$ and from murine and human placenta [21-23].

Recently, several studies have demonstrated that hemogenic endothelial (HE) cells are the direct precursors of HSCs; the most compelling evidence was obtained by tracing hematopoietic cell emergence in the AGM region of both zebrafish and mouse [24, 25, 26]. Human early hematopoietic cells have also been shown to be generated from the blood-forming endothelium located in the embryonic aorta and vitelline artery $[27,28]$. A recent study described that the hematopoietic differentiation of mESCs occurred via a HE stage [29]. During hESC differentiation, primitive endothelial cells with hemangioblastic properties have been shown to give rise to hematopoietic cells [30]. In addition, hematopoietic progenitors expressing CD43 have been identified in the OP9 co-culture differentiation system [31]. However, the mechanisms regulating the emergence of $\mathrm{CD} 43^{+}$HPCs from $\mathrm{HE}$ cells in vivo and in vitro have not been well studied.

In this study, we developed a stepwise hematopoietic differentiation strategy of hESCs by recapitulating embryonic hematopoiesis through the sequential stages of $\mathrm{BRACHYURY}^{+} \mathrm{PS} / \mathrm{KDR}^{+}$early mesoderm induction, $\mathrm{CD} 31^{+}$-enriched $\mathrm{HE}$ cell specification, $\mathrm{CD} 43^{+} \mathrm{CD} 45^{-}$ hematopoietic cell emergence and $\mathrm{CD} 43^{+} \mathrm{CD} 45^{+}$hematopoietic progenitor generation using a chemically defined strategy. On the basis of this strategy, we studied the mechanisms regulating the emergence of $\mathrm{CD} 43^{+}$ HPCs from hESC-derived HE cells. We determined that TGF $\beta$ inhibition enhanced the generation of HPCs by combining with VEGF and bFGF, which allowed us to develop an efficient strategy to direct the differentiation of hESCs to HPCs.

\section{Results}

Development of a stepwise hematopoietic differentiation strategy by recapitulating embryonic hematopoiesis in a chemically defined medium

Our previous work showed that the short-term treatment of hESCs cultured in a monolayer with BMP4 in a chemically defined medium (CDM) efficiently induced BRACHYURY- and KDR-expressing early mesoderm cells that possessed hematopoietic potential [32]. On the basis of this differentiation system, we further induced the hematopoietic differentiation. We found that some differentiated $\mathrm{CD} 31^{+}$cells at day 4 with sheet morphology gradually generated non-adherent hematopoietic cells (Supplementary information, Figure S1A). This process was similar to the results from another study that hematopoietic cells were generated from mouse ESCs through HE cells with sheet morphology [29]. Thus, we supposed that the CD31 $1^{+}$cells generated from hESCs contained HE cells. We further identified that these CD $31^{+}$-enriched HE cells exhibited endothelial characteristics and had the potential to generate hematopoietic cells (Supplementary information, Figure S1B and $\mathrm{S} 1 \mathrm{C})$. In addition, we found that sorted $\mathrm{CD} 31^{+}$cells at day 5 could gradually undergo transition into $\mathrm{CD} 43^{+}$ hematopoietic progenitors and that these $\mathrm{CD} 43^{+}$cells contained hematopoietic progenitors (Supplementary information, Figure S1D). Our results are consistent with previous studies $[30,31]$. On the basis of our identification of $\mathrm{CD} 43^{+}$HPCs arising from $\mathrm{CD} 31^{+}$-enriched $\mathrm{HE}$ cells, we traced the entire hematopoietic differentiation process from hESCs using a flow cytometry analysis. We found that BRACHYURY ${ }^{+} / \mathrm{KDR}^{+}$cells, $\mathrm{CD} 31^{+}$cells, $\mathrm{CD} 43^{+}$cells and $\mathrm{CD} 45^{+}$cells emerged sequentially during hematopoietic differentiation from hESCs (Figure 1A). Thus, we proposed a model to predict the entire process of the hematopoietic differentiation of hESCs that recapitulated the main stages of early hematopoietic development: (1) the commitment of BRACHYURY ${ }^{+} /$ $\mathrm{KDR}^{+} \mathrm{PS} /$ early mesoderm from hESCs; (2) the specification of HE cells expressing CD31 from the early mesoderm cells; (3) the emergence of $\mathrm{CD} 31^{+} \mathrm{CD} 43^{+} \mathrm{CD} 45$ hematopoietic cells from the HE cells; and (4) the generation of $\mathrm{CD} 43^{+} \mathrm{CD} 45^{+} \mathrm{HPCs}$ from $\mathrm{CD} 31^{+} \mathrm{CD} 43^{+} \mathrm{CD} 45^{-}$ progenitors (Figure 1B). This differentiation method and the defined culture system allowed us to elucidate the mechanisms underlying each hematopoietic developmental step, particularly the critical step of hematopoietic cells emerging from HE cells. 
$V E G F$ is essential and sufficient to generate $H E$ cells and the subsequent hematopoietic progenitors from early mesoderm cells, and bFGF is synergistic

Using our developed defined system, we first investigated the factors that regulate the HE cell specification from early mesoderm cells by testing various signaling factors that are involved in hematopoietic development (Supplementary information, Table S1). We added these factors to the differentiated cells after 2 days of treatment with activin A and BMP4, and then analyzed the generation of $\mathrm{CD} 31^{+}$cells at day 4 . Surprisingly, we found that among the factors that we tested, only VEGF induced the generation of $\mathrm{CD} 31^{+}$cells (Figure $2 \mathrm{~A}$ ). We then examined the effects of the VEGF concentration on the generation of $\mathrm{CD} 1^{+}$cells and found a dose-dependent response within the tested concentration range (10-80 ng/ $\mathrm{ml}$; Supplementary information, Figure S2A, upper lane). We tested higher VEGF concentrations, but the generation of $\mathrm{KDR}^{+} \mathrm{CD} 31^{+}$cells was not increased (Supplementary information, Figure S2B). When combined with VEGF, bFGF showed a significant synergistic effect in inducing $\mathrm{CD} 31^{+}$cells (Figure $2 \mathrm{~B}$ and $2 \mathrm{C}$ ). However, this effect of bFGF was abrogated when VEGF was added at high concentrations (40-80 ng/ml) (Supplementary information, Figure S2A, lower lane).

These VEGF-induced $\mathrm{CD} 31^{+}$cells transitioned into $\mathrm{CD} 43^{+}$hematopoietic progenitors upon further treatment with VEGF or VEGF + bFGF (Figure 2D), suggesting

A
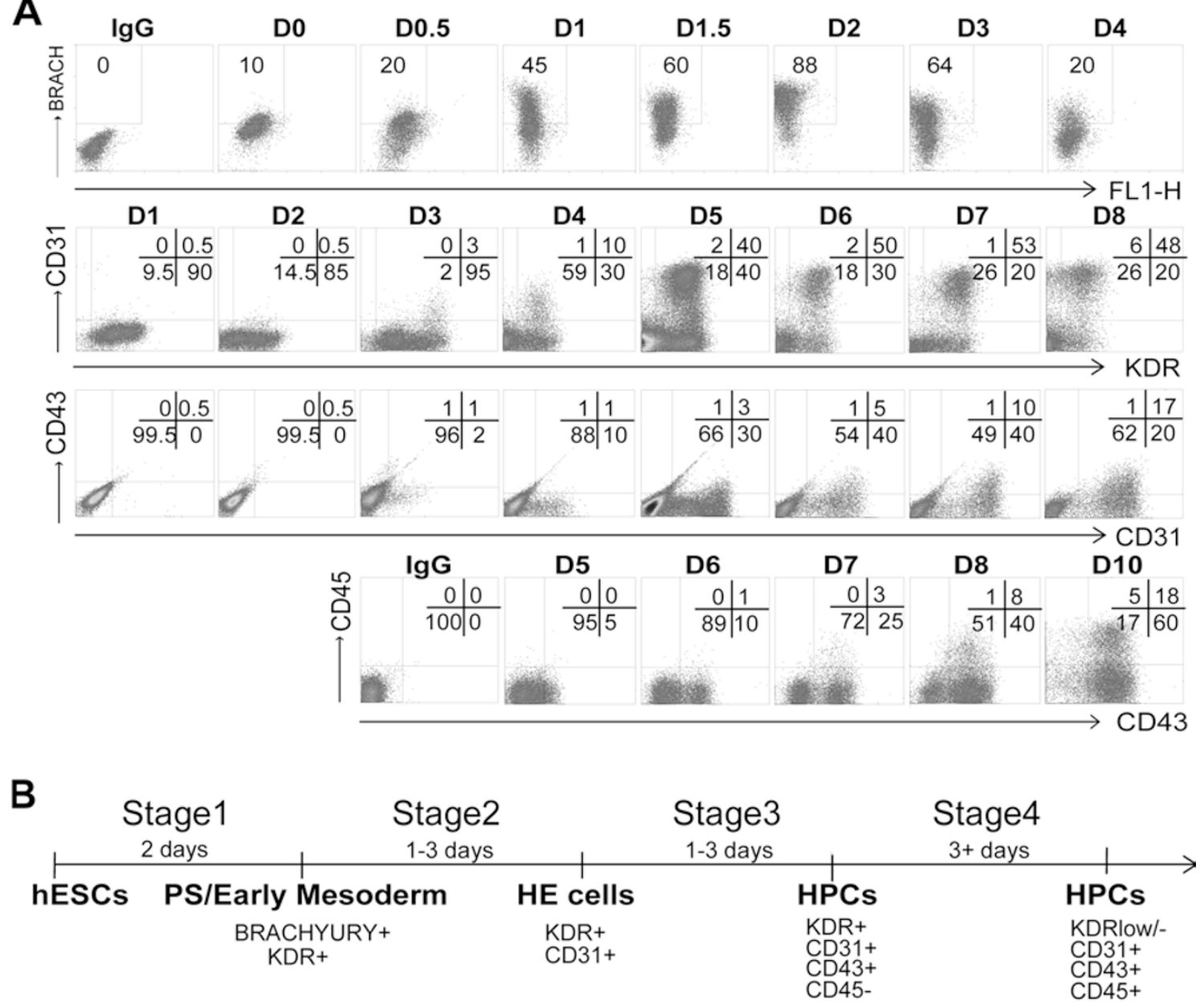

Figure 1 Development of a hematopoietic differentiation strategy by recapitulating embryonic hematopoiesis in a chemically defined medium. (A) Kinetics of BRACHYURY (BRACH), KDR, CD31, CD43 and CD45 expression during the hematopoietic differentiation of hESCs from D0 to D10. HESCs were differentiated with 2 days of BMP4 + bFGF (BF) treatment, followed by 3 days of VEGF + bFGF (VF) treatment. CD31 ${ }^{+}$cells sorted at day 5 were further cultured in hematopoietic culture medium (HCM) containing SCF, TPO and IL3. The number shown is the percentage of cells in the gates. These results are representative of more than three experiments. (B) The scheme of a stepwise hematopoietic differentiation strategy of hESCs. 

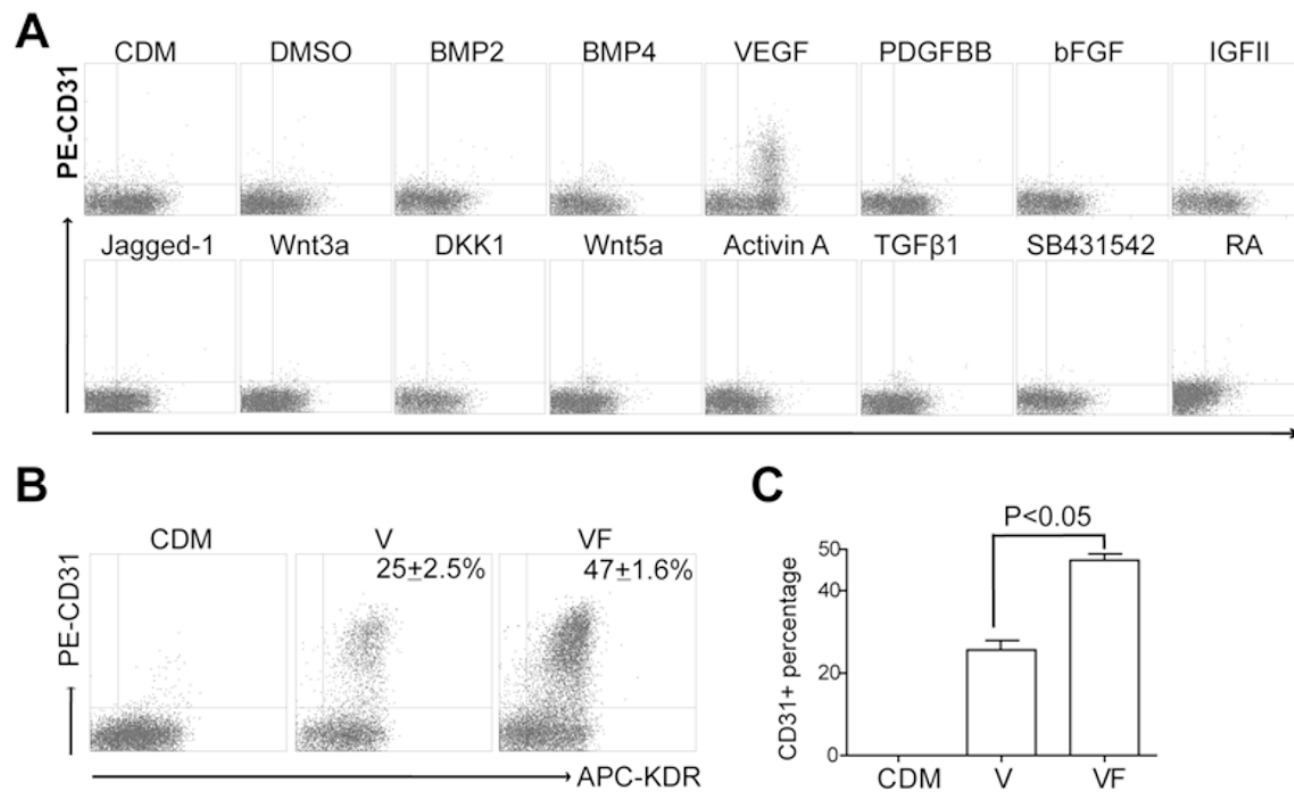

SFTIL3

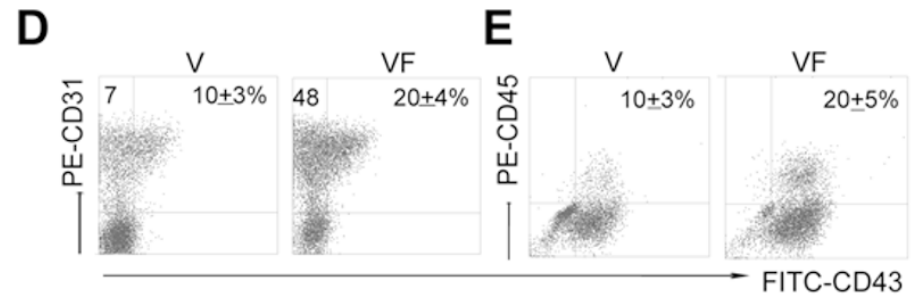

C
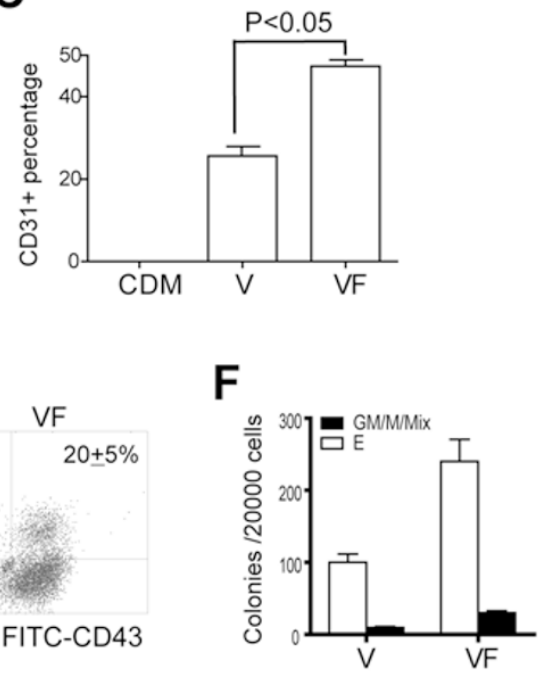

Figure $2 \mathrm{HE}$ cells and CD43 ${ }^{+}$hematopoietic cells are specified by VEGF, and bFGF is synergetic with VEGF. (A) The generation of $\mathrm{CD} 31^{+}$cells from hESC-derived mesoderm cells induced by different signal factors. (B, C) bFGF displays synergistic effects with VEGF to increase CD31 ${ }^{+} \mathrm{HE}$ cell generation from hESC-derived early mesoderm cells. (B) Analysis of CD31 cells generated from hESC-derived early mesoderm cells after 3 days of VEGF (V) alone or VEGF + bFGF (VF) treatment. The results from a representative experiment are presented as means $\pm \operatorname{sem}(n=6)$. (C) Statistical analysis of $\mathbf{B}$ using a onetailed Student's $t$-test, $P<0.05$. (D, E) VEGF-induced cells can be further differentiated into CD $45^{+} \mathrm{CD} 43^{+} \mathrm{HPCs}$, and bFGF exerts synergistic effects. (F) CFU assay of day 8 differentiated cells. The data presented are representative of three experiments.

that VEGF is sufficient to specify HE cells enriched with $\mathrm{CD} 31^{+}$cells from the early mesoderm and it can further commit these HE cells into CD43 $3^{+}$HPCs. After further culturing these differentiated $\mathrm{CD} 43^{+}$cells in hematopoietic culture medium (HCM) containing SCF, TPO and IL3, CD $45^{+}$hematopoietic progenitors were generated (Figure 2E and 2F).

$V E G F, b F G F, T G F \beta$ and retinoic acid signals regulate the transition of $\mathrm{CD} 43^{+}$hematopoietic cells from $\mathrm{HE}$ cells

We further identified the factors that regulate the generation of $\mathrm{CD} 43^{+}$hematopoietic cells from $\mathrm{hESC}$-derived HE cells by administering potential hematopoietic signaling activators or inhibitors (Supplementary informa- tion, Table S1) to day 4 differentiated cells, when CD43 hematopoietic cells had not yet emerged (Figure 1A, the third lane). We detected $\mathrm{CD} 31^{+} \mathrm{CD} 43^{+}$cells at day 6 generated in response to different treatments using a flow cytometry analysis. We found that VEGF, bFGF, TGF $\beta$ and retinoic acid (RA) signals regulated the transition of $\mathrm{CD} 31^{+}$cells into $\mathrm{CD} 43^{+}$hematopoietic cells (Figure $3 \mathrm{~A}$ ). VEGF was identified not only as an inducer to specify CD $31^{+}$-enriched HE cells from the early mesoderm but also to further commit $\mathrm{HE}$ cells into $\mathrm{CD} 43^{+}$hematopoietic cells. The inhibition of bFGF using SU5402 almost completely inhibited the generation of $\mathrm{CD} 43^{+}$cells from HE cells, and the addition of bFGF to the HE cells enhanced the generation of hematopoietic cells from HE cells. These data suggested that bFGF played important 


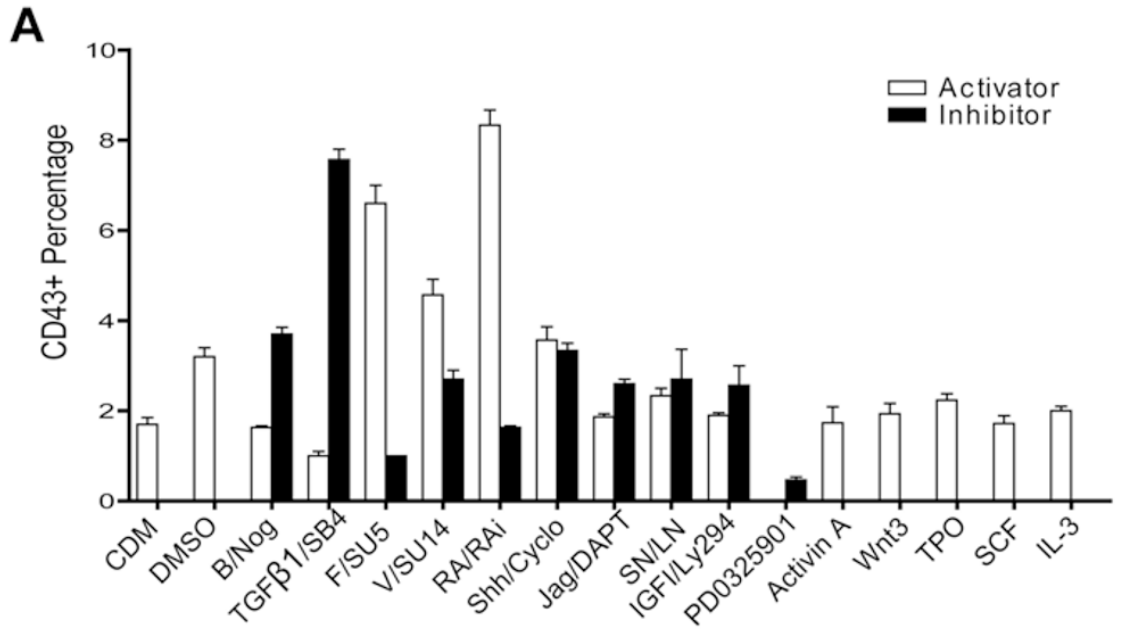

B
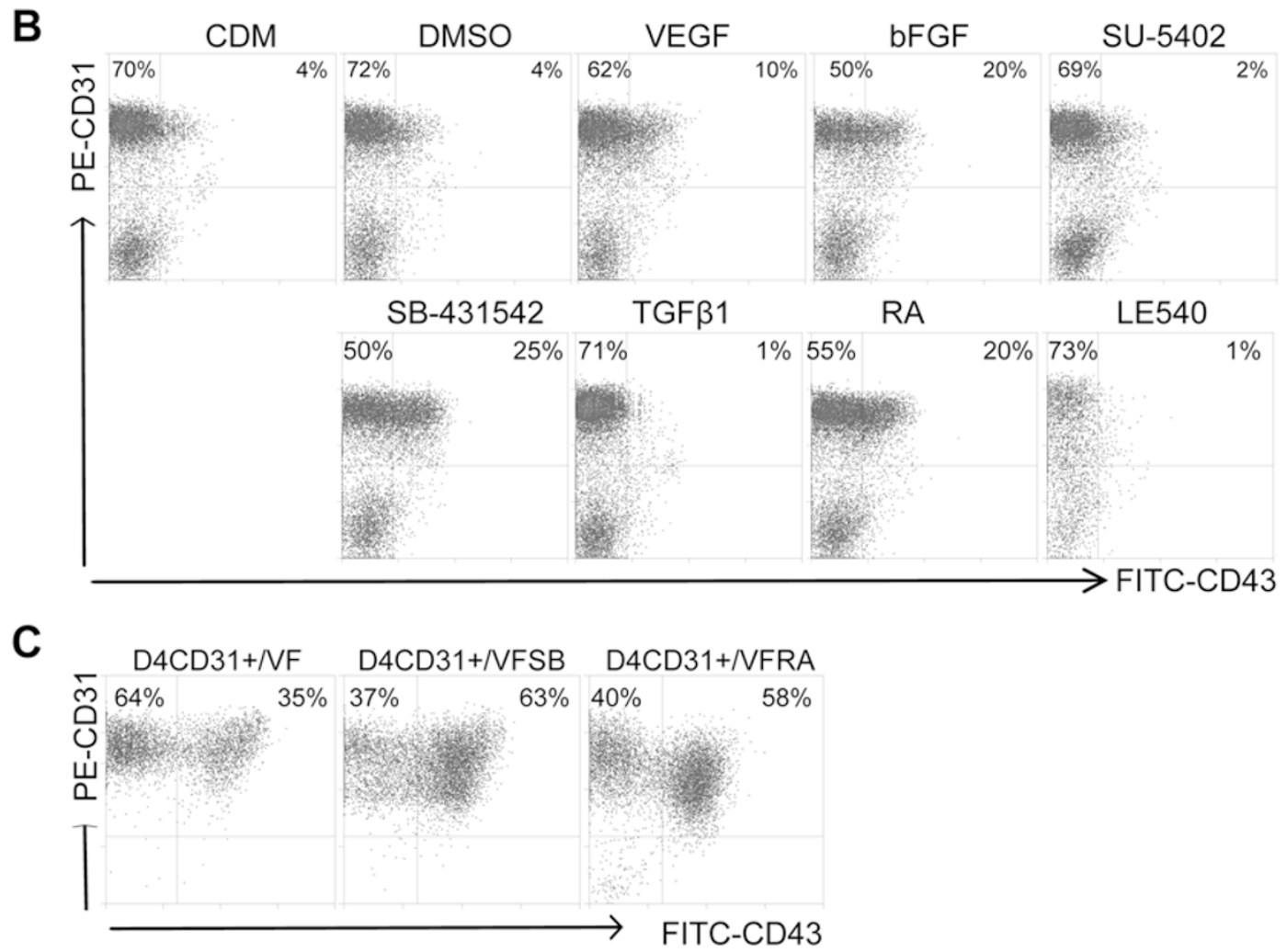

Figure 3 Identification of the signals regulating the transition of $\mathrm{CD} 31^{+}$-enriched $\mathrm{HE}$ cells into CD43 ${ }^{+}$hematopoietic cells. (A) Analysis of $\mathrm{CD} 31^{+} \mathrm{CD} 43^{+}$hematopoietic cells induced by signal factors. hHESCs plated at $1-2 \times 10^{5}$ cells/well in 12 -well plates were differentiated after 2 days of treatment with BMP4 + bFGF (BF) and 2 days of treatment with VEGF + bFGF (VF) and were further differentiated by addition of the indicated signal factors (Supplementary information, Table S1): BMP4 (B), Noggin (Nog), SB431542 (SB4), bFGF (F), SU5402 (SU5), VEGF (V), SU1498 (SU14), the RA inhibitor LE540 (RAi), cyclopamine (Cyclo), Jagged 1 (Jag), SNAP (SN) and L-NAME (LN). (B) The effect of signals, including VEGF, bFGF, RA and TGF $\beta$, on the generation of CD43 ${ }^{+}$hematopoietic cells from hESC-derived cells. The concentrations used were $40 \mathrm{ng} / \mathrm{ml}$ VEGF, $50 \mathrm{ng} / \mathrm{ml}$ bFGF, $5 \mu \mathrm{M}$ SU5402, $10 \mu \mathrm{M}$ RA, $4 \mu \mathrm{M}$ LE540 (the inhibitor of RA), $10 \mathrm{ng} / \mathrm{ml}$ TGF $\beta 1$ and $10 \mu \mathrm{M}$ SB 431542 in chemically defined medium (CDM), and CDM with $0.1 \%$ DMSO was used as a control (DMSO). Each of the factors was added to differentiated cells after 2 days of activin $A+B M P 4(A B)$ and 2 days of VF treatment, and the expression of CD43 and CD31 was tested in differentiated cells on day 6 using flow cytometry. (C) SB431542 enhances the generation of CD43 ${ }^{+}$ hematopoietic cells from day 4 sorted $C D 31^{+}$cells. After 2 days of treatment with $A B$ and 2 days of treatment with VF, CD31 ${ }^{+}$ cells were sorted from differentiated cells and treated with VFSB or VFRA using VF as the control. Cells were then analyzed at day 6 . 
roles in generating $\mathrm{CD} 43^{+}$hematopoietic cells from $\mathrm{HE}$ cells. Interestingly, we found that the TGF $\beta$ inhibitor SB431542 (SB) promoted the transition of CD3 $1^{+}$to CD $43^{+}$cells, while TGF $\beta 1$ completely inhibited the emergence of $\mathrm{CD} 43^{+}$cells (Figure 3A and 3B). RA displayed a promoting effect, while its inhibitor LE540 completely abolished the emergence of $\mathrm{CD} 43^{+}$cells (Figure $3 \mathrm{~A}$ and 3B). We previously demonstrated a similar effect of RA on the hematopoietic differentiation of hESCs using the EB strategy [33]. In addition, we found that SB and RA acted on $\mathrm{CD} 31^{+}$cells to enhance the transition of $\mathrm{CD} 43^{+}$ cells from sorted $\mathrm{CD} 31^{+}$cells (Figure $3 \mathrm{C}$ and Supplementary information, Figure S3).

SB431542 enhances hematopoietic gene expression and the production of $\mathrm{CD} 3^{+}$hematopoietic cells

As SB was effective in enhancing the transition of $\mathrm{CD}_{4} 3^{+}$hematopoietic cells from HE cells, we further studied SB functions on hematopoiesis at different developmental stages. We administered SB from days 0-4 to the control condition that reflected 2 days of treatment with activin A+ BMP4 and 4 days of treatment with VEGF + bFGF (VF). We tested the gene expression of differentiated cells with different treatments at day 6 . When SB was added on the first day, the expression of mesoderm and hematopoietic genes including $K D R$, CD31, CD43, SCL, GATA 1, RUNX1, C-MYB, GATA2 and IKAROS was completely or mostly inhibited (Figure 4A). This result can be explained by the inhibitory effect of SB on activin $\mathrm{A}$ /nodal signal functioning at the first differentiation stage (data not shown). However, when SB was added at day 4 , hematopoietic transcription factors, such as RUNX1, C-MYB, GATA 2, GATA 1, SCL, $I K A R O S$ and $P U .1$, were enhanced from two- to fivefold (Figure 4A). In addition, we found that the expressions of KDR and CD31 were not changed, but the expression of CD43 was enhanced (Figure 4A), suggesting that SB specifically enhanced hematopoietic differentiation at the step of the generation of hematopoietic cells from HE cells.

On the basis of a flow cytometry analysis, we found that SB treatment on day 4 enhanced the generation of CD $43^{+}$cells up to $35 \%-40 \%$, while the differentiation efficiency was $\sim 15 \%-20 \%$ in response to VF treatment (Figure 4B, upper lane). Significantly, the generation of $\mathrm{CD} 43^{+} \mathrm{CD} 235 \mathrm{a}^{-}$cells, which have been reported to enrich hematopoietic progenitors [30], was enhanced up to around $20 \%$ yield in response to VEGF + bFGF + SB (VFSB) treatment vs around $8 \%$ yield in response to VF treatment (Figure 4B, lower lane). Regarding the production of $\mathrm{CD}_{4} 3^{+}$cells from hESCs, VFSB treatment from days 4-6 enhanced the generation of $\mathrm{CD} 43^{+}$cells by two- to threefold compared with VF treatment (Figure 4D), although the total differentiated cell numbers were similar between these two groups (Figure 4C). We also found that SB exhibited similar effects in enhancing the generation of $\mathrm{CD}_{4} 3^{+}$cells during $\mathrm{H} 9$ differentiation (Supplementary information, Figure S4A). Therefore, these data suggested that SB acted in the hematopoiesis of hESCs, specifically at the stage in which $\mathrm{CD}_{4} 3^{+}$hematopoietic cells emerged from HE cells.

In contrast to the effect of SB, exogenous TGF $\beta 1$ decreased the generation of $\mathrm{CD} 31^{+}$cells and completely blocked the transition of $\mathrm{CD}_{4} 3^{+}$cells from $\mathrm{CD} 31^{+}$cells whenever it was added on day 2 or 4 (Figure 4E). In addition, we detected TGF $\beta 1$ expression in these differentiated cells generated in response to VEGF, bFGF and TGF $\beta 1$ (VFT), VF and VFSB treatments; the addition of TGF $\beta 1$ increased the endogenous TGF $\beta 1$ expression, while the addition of SB decreased the endogenous TGF $\beta 1$ expression (Supplementary information, Figure S4B). These data suggested that TGF $\beta 1$ had an inhibitory effect on hematopoietic differentiation and SB probably abrogated its inhibitory effect on hematopoietic cell generation.

The inhibition of TGF $\beta$ by SB431542 promoted the generation of $\mathrm{HESC}$-derived HPCs

We further studied these VFSB- and VF-induced hematopoietic cells by continuously culturing them in $\mathrm{HCM}$ containing SCF, TPO and IL3 in suspension. We found that VFSB-induced cells generated more $\mathrm{CD} 43^{+} \mathrm{CD} 45^{+}$ cells than VF-induced cells ( $\sim 14 \%$ vs $4 \%$ at day $8,38 \%$ vs $16 \%$ at day 12 and $50 \%$ vs $20 \%$ at day 18 ; Figure $5 \mathrm{~A}$ $5 \mathrm{C})$. When cells were further cultured to day 28 , most of the VFSB-induced hematopoietic cells were viable and displayed proliferative abilities, whereas most of the VF-induced cells were dying (Figure 5D, right). Among these live cells, most of them expressed CD45 (Figure $5 \mathrm{D}$, left).

In line with this result, VFSB-induced cells produced more hematopoietic colonies, including CFU-GM, CFU$\mathrm{G}$ and CFU-mix, than VF-induced cells (Figure 5E and $5 F)$. In particular, after 28 days of culture, the VFSBinduced cells still generated CFU-E, CFU-G, CFU-M and CFU-GM colonies, but VF-induced cells lost that capacity (Figure 5G).

We also analyzed the globin expression of VF- and VFSB-induced cells at day 8 of differentiation. We found that the primitive globins, including $\varepsilon^{-}, \gamma$ - and $\zeta$-globin, were expressed at similar level under these two conditions (Figure $5 \mathrm{H}$, left). However, VFSB-generated hematopoietic cells expressed over twofold more $\beta$-globin than VF-induced hematopoietic cells (Figure 5H, right). 
A
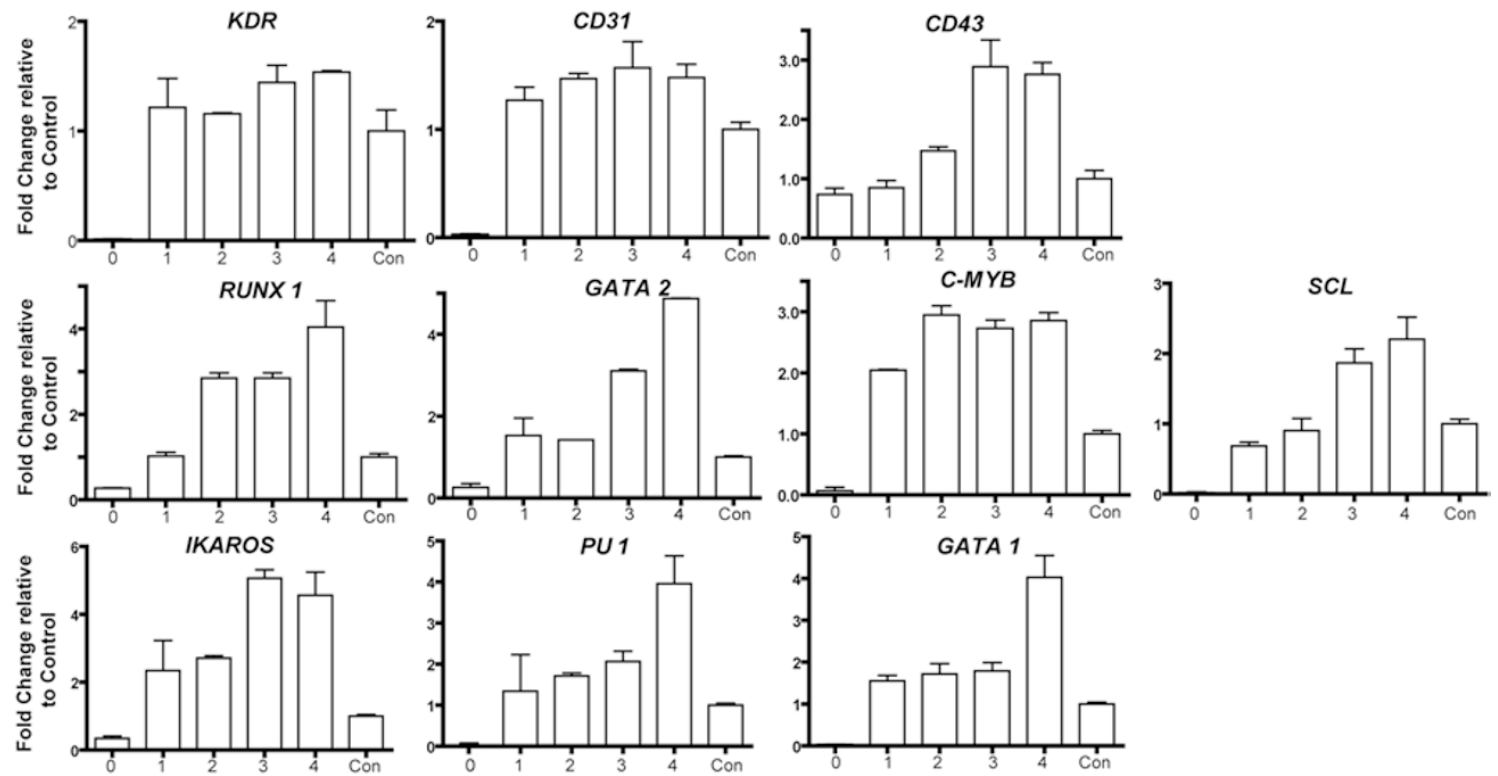

B

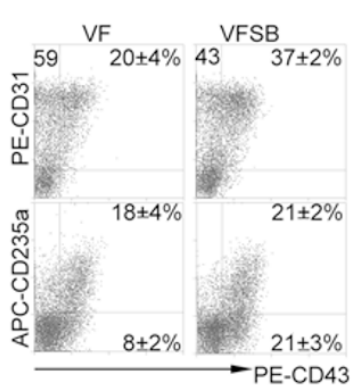

C

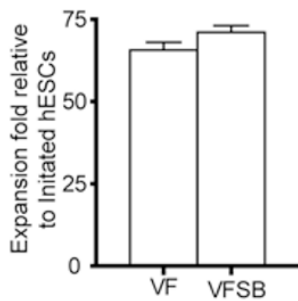

D

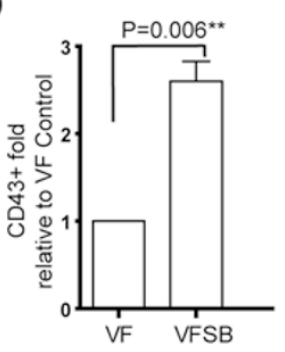

E

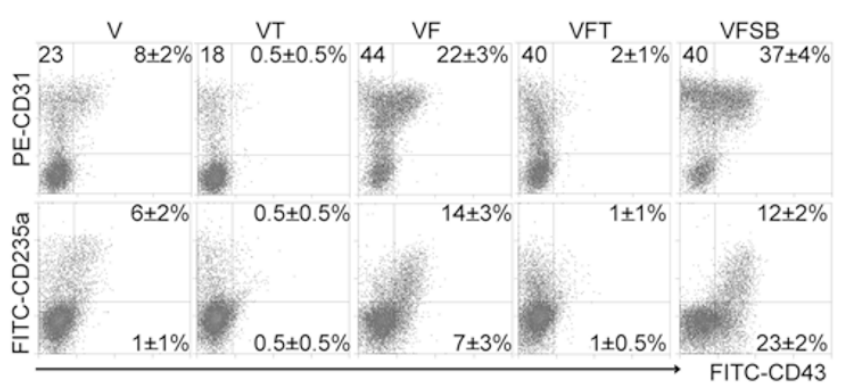

Figure 4 SB431542 (SB) enhances hematopoietic gene expression and greatly enhances the production of CD43 ${ }^{+}$hematopoietic cells. (A) Expression levels of mesoderm and hematopoietic genes after SB addition each day from days 0-4 (0, 1, 2, 3 and 4). Control cells (Con) were treated with AB for 2 days, followed by treatment with VF for 4 days. Cells differentiated under these conditions were collected at day 6 and analyzed using Q-PCR. (B) SB treatment at the third step greatly enhanced the generation of $\mathrm{CD}_{4}{ }^{+} \mathrm{CD} 235 \mathrm{a}^{-}$cells enriched for HPCs. (C) The fold expansion of differentiated cells at day 6 relative to the initiated hESCs. The treatment of VF from days 2-6 was given to the VF group. VF treatment from days 2-4 and VFSB treatment from days 4-6 was given to the VFSB group. (D) The sorted CD43 ${ }^{+}$cells generated in response to VFSB were two- to threefold compared to the VF control, which was significant as determined using the one-tailed $t$-test, $P=0.006$ $<0.05$. (E) Exogenous TGF $\beta 1$ greatly reduced the generation of CD31 $\mathrm{HE}$ cells and completely blocked the generation of $\mathrm{CD}_{3}{ }^{+}$cells from CD31 ${ }^{+}$cells. Non-sorted differentiated cells were treated with VEGF (V), VTGF $\beta 1$ (VT) or VFSB-431542 (VFSB) from days 2-4 and analyzed at day 6. The data presented are representative of three experiments.

In addition, we analyzed the $\beta$-globin expression of HPCs cultured in HCM containing EPO by a flow cytom- etry analysis and found that VFSB-generated HPCs produced nearly twofold $\beta$-globin-expressing erythrocytes 
A

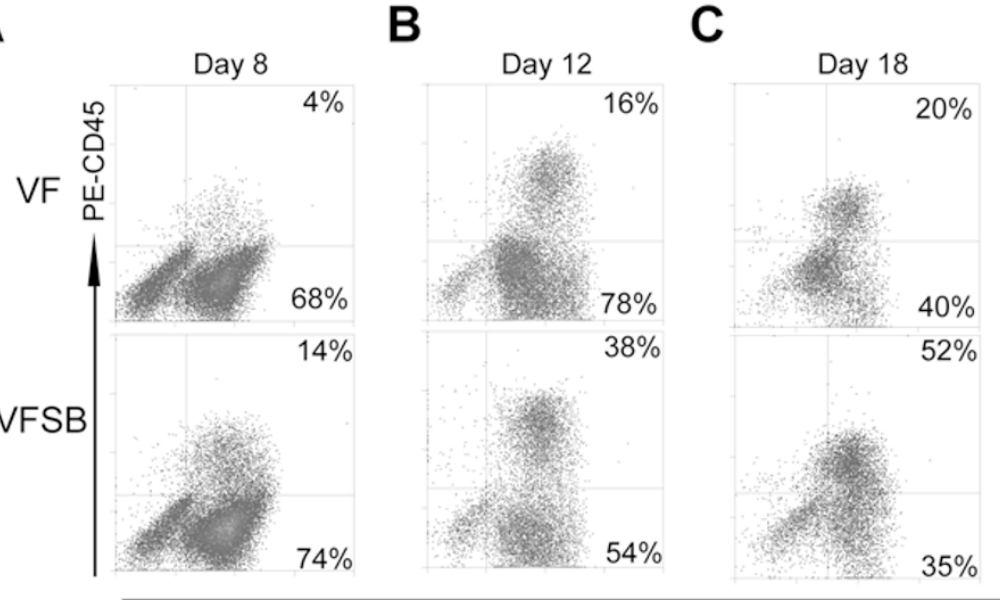

D
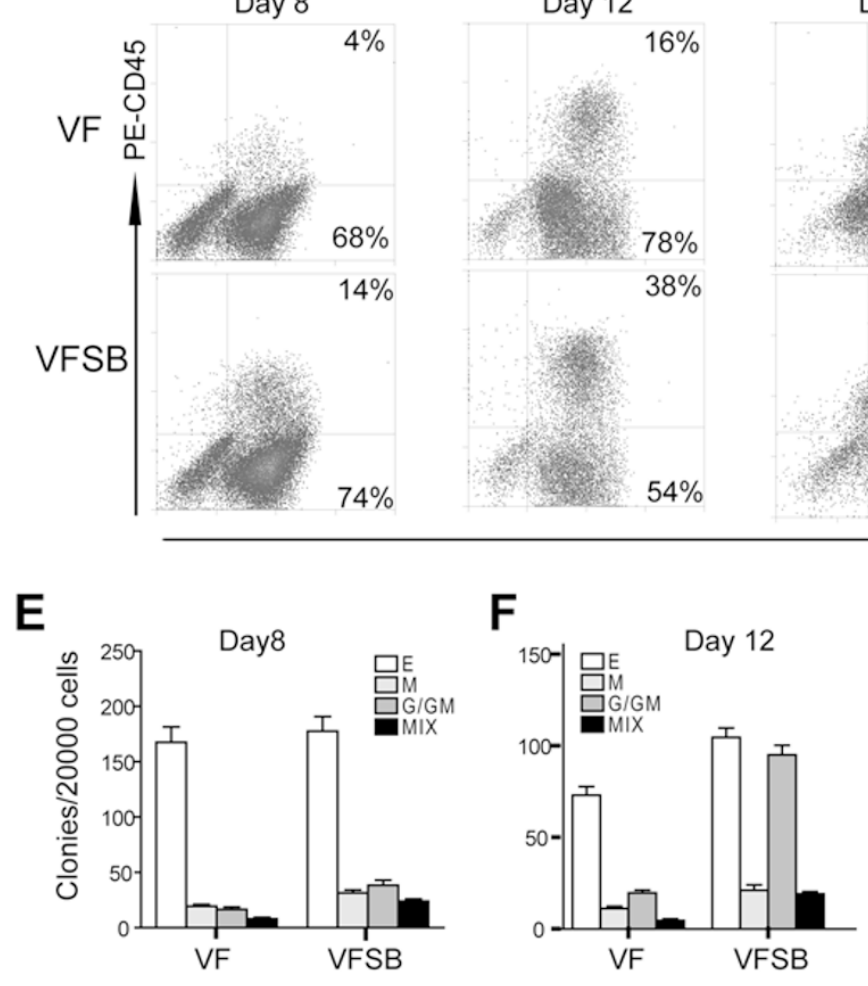

G
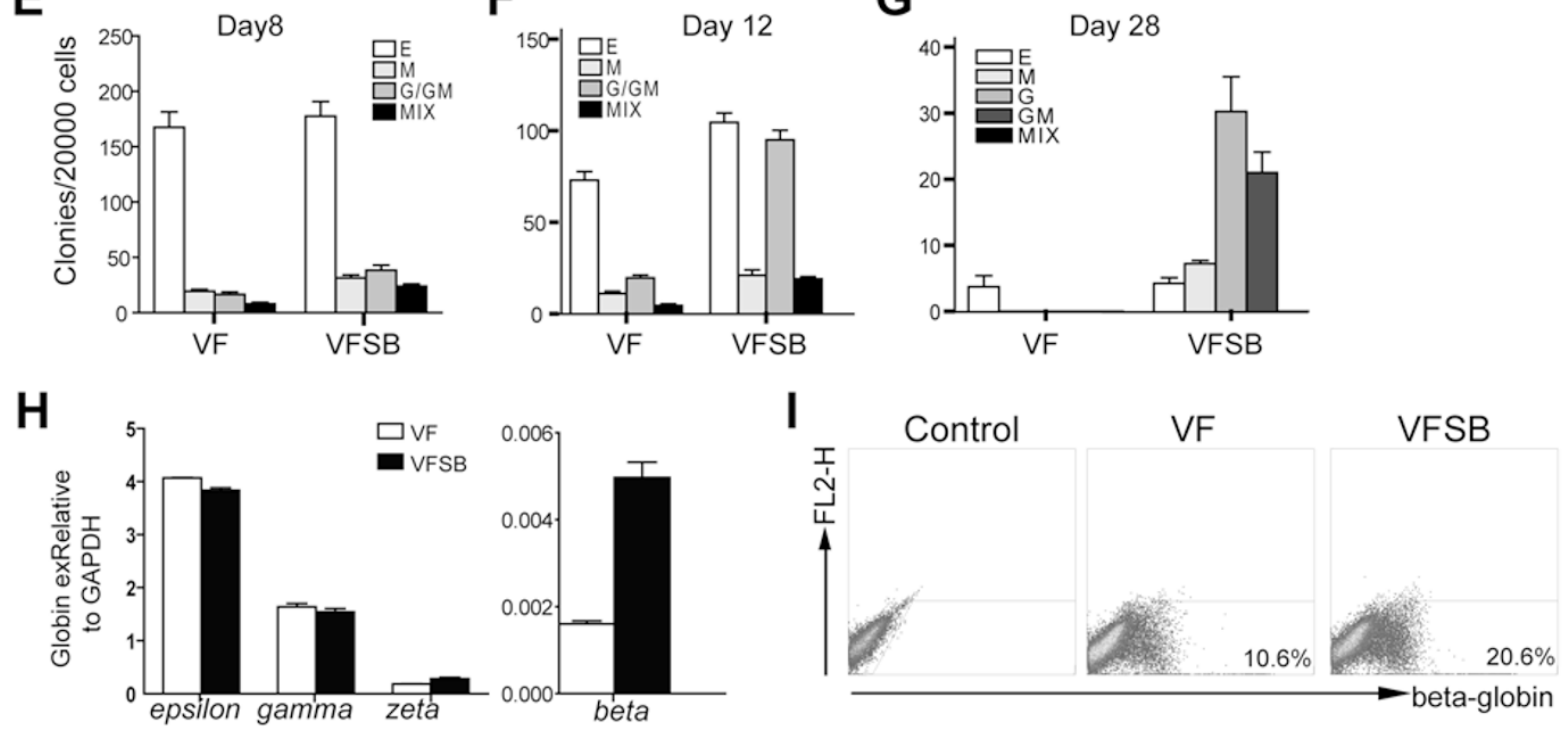

Figure 5 SB431542 (SB) promoted the generation of HPCs from the HE stage. (A-C) The generation of CD43 ${ }^{+} \mathrm{CD} 45^{+} \mathrm{HPCs}$ was more enhanced in response to treatment with VFSB than with VF. Differentiated cells induced after 2 days of AB treatment and 4 days of VF or VFSB treatment were further cultured in HCM and analyzed at day 8 (A), day 12 (B) and day 18 (C). (D) SB-treated cells generated HPCs capable of surviving and proliferating until day 28. Many live and some proliferating hematopoietic cells were found under the VFSB-treated condition, while only a few live hematopoietic cells were found under the VF-treated condition (right). (E-G) Colony-forming assay for differentiated cells at days 8, 12 and 28 , respectively. The data are presented as means $\pm \operatorname{sem}(n=3)$ from one representative experiment. Because a few CFU-G colonies were generated among HPCs at day 8 and day 12, the CFU-G and CFU-GM colonies were counted together. (H) Hemoglobin expression in differentiated cells at day 8 . The hemoglobin levels, including $\varepsilon$-, $\gamma$ - and $\zeta$-globin (left) and $\beta$-globin (right), were detected. The data are presented as means $\pm \operatorname{sem}(n=3)$. (I) VF- and VFSB-treated hematopoietic progenitors were further cultured for 2 weeks in HCM containing SCF and EPO, and cells were analyzed for $\beta$-globin expression with a flow cytometry analysis.

than VF-generated HPCs (Figure 5I and Supplementary information, Data S1). All these results indicated that the inhibition of TGF $\beta$ by SB beginning at the HE cell stage enhances the generation of HPCs that are capable of sustaining proliferation in vitro for up to 1 month.
SB431542 regulates the apoptosis but not the proliferation of hESC-derived cells

We next tested whether the enhanced hematopoiesis in response to SB resulted from the decreased apoptosis or enhanced proliferation of VFSB-induced hematopoietic cells. We evaluated Annexin $\mathrm{V}^{+}$ratios among differenti- 
A

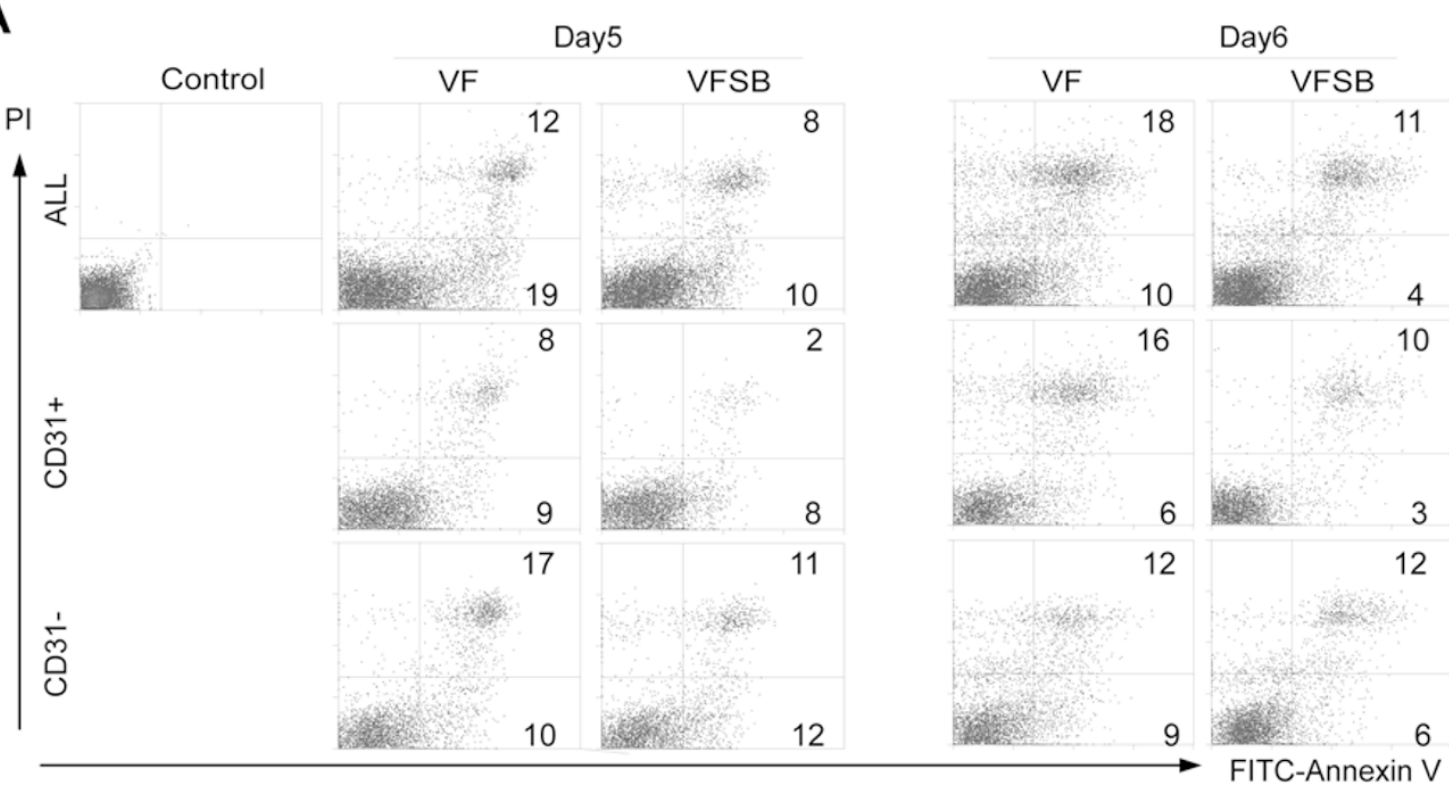

B

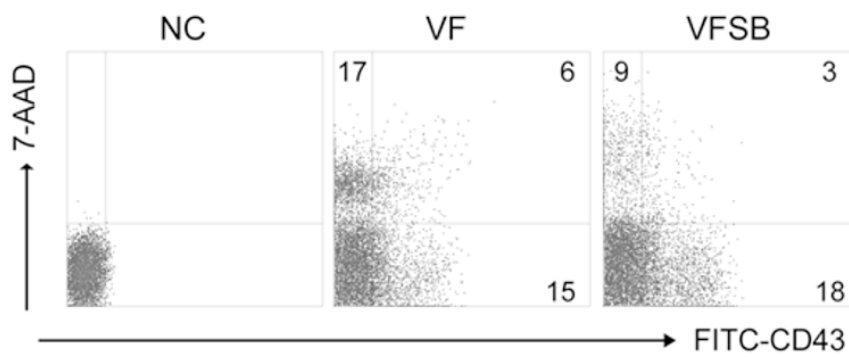

C

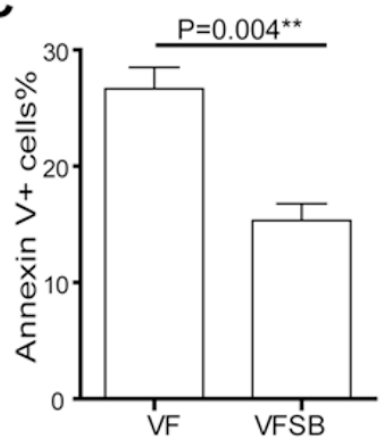

D

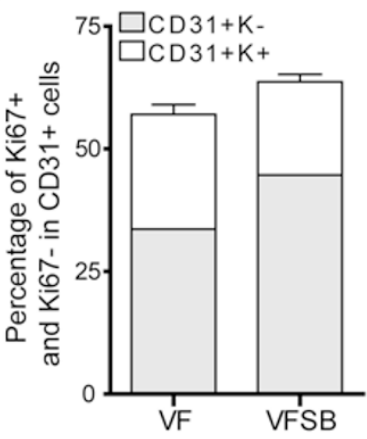

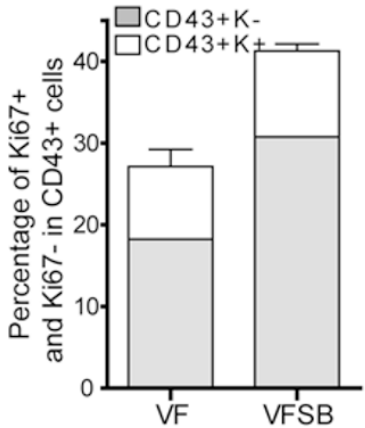

Figure 6 Analysis of apoptosis and proliferation rates of hematopoietic cells treated with SB431542. (A) Apoptosis analysis of day 5 and 6 differentiated cells after 2 days of VF or VFSB treatment. Apoptosis of all the differentiated cells, CD31 and CD31 $1^{-}$cells, were analyzed as $\mathrm{PI}^{-} /$Annexin $\mathrm{V}^{+}$and $\mathrm{PI}^{+} /$Annexin $\mathrm{V}^{+}$. (B) The apoptosis of CD43 ${ }^{+}$cells was analyzed using 7-AAD after 2 days of treatment with VF or VFSB. (C) Statistical analysis of Annexin $\mathrm{V}^{+}$cells of (A). The apoptosis results are representative of three experiments. (D) Evaluation of the proliferation rate of differentiated cells by analyzing Ki67 ${ }^{+}$cells in $\mathrm{CD} 31^{+}$cells and $\mathrm{Ki}^{+} 7^{+}$cells in $\mathrm{CD}_{4}{ }^{+}$cells. Differentiated cells were analyzed using Ki67 and CD31/CD43 staining. The data presented are representative of three experiments.

ated cells at days 5 and 6 and found $\sim 10 \%$ decrease in Annexin $\mathrm{V}^{+}$apoptotic cells in VFSB-induced cells compared with the VF-induced control (Figure 6A and 6C). By further analyzing the apoptosis of $\mathrm{CD} 31^{+}$and $\mathrm{CD} 31^{-}$ cells generated with VF or VFSB treatment, we found that VFSB decreased the apoptosis ratio mainly in the $\mathrm{CD} 31^{+}$cells (Figure 6A). In addition, we analyzed the apoptosis of $\mathrm{CD} 43^{+}$cells generated from VF or VFSB 
conditions by co-staining CD43 with 7-AAD, we found that the ratio of VFSB-induced $\mathrm{CD} 43^{+} 7-\mathrm{AAD}^{+}$cells was lower than that of VF-induced $\mathrm{CD}^{2} 3^{+} 7-\mathrm{AAD}^{+}$cells (Figure 6B).

We assessed the proliferation rates of the differentiated cells by analyzing the percentages of $\mathrm{Ki}^{+} 7^{+}$cells in $\mathrm{CD} 31^{+}$and $\mathrm{CD} 43^{+}$cells. The results showed that $\mathrm{Ki} 67^{+} \mathrm{CD} 31^{+} / \mathrm{CD} 31^{+}$and $\mathrm{Ki} 67^{+} \mathrm{CD} 43^{+} / \mathrm{CD} 43^{+}$ratios showed no significant discrepancy between VFSB- and VF-induced $\mathrm{CD} 31^{+}$and $\mathrm{CD} 43^{+}$cells (Figure 6D). We counted the differentiated cells at day 6 and found that they expanded over 60 -fold compared with the initiated hESCs, but there was no significant difference in expansion between VF- and VFSB-induced cells (Figure 4C). Our data supported that the enhanced hematopoiesis induced by SB probably results from the regulation of apoptosis but not from the regulation of the proliferation of hESC-derived hematopoietic cells.

Efficient generation of hematopoietic progenitors from hESCS

After we defined the critical factors governing the generation of HE cells and HPCs and on the basis of pre- vious studies [1, 5, 8-11, 32, 33], we developed a fourstep hematopoietic differentiation strategy of hESCs in a CDM. We treated hESCs with $50 \mathrm{ng} / \mathrm{ml}$ activin A and 50 $\mathrm{ng} / \mathrm{ml} \mathrm{BMP} 4$ for 2 days at the first stage, $40 \mathrm{ng} / \mathrm{ml}$ VEGF and $50 \mathrm{ng} / \mathrm{ml} \mathrm{bFGF}$ for 2 days at the second stage, $40 \mathrm{ng} /$ $\mathrm{ml}$ VEGF, $50 \mathrm{ng} / \mathrm{ml} \mathrm{bFGF}$ and $20 \mu \mathrm{M}$ SB for 2 days at the third stage and $50 \mathrm{ng} / \mathrm{ml} \mathrm{SCF}, 50 \mathrm{ng} / \mathrm{ml}$ TPO and 50 $\mathrm{ng} / \mathrm{ml}$ IL3 at the final stage (Figure 7A). This induction approach resulted in $>90 \%$ BRACHYURY $^{+}$PS cells in 2 days and $>90 \% \mathrm{KDR}^{+}$mesoderm cells and over $80 \%$ $\mathrm{CD} 31^{+}$cells in 5 days. Of these, nearly $40 \%$ of CD $31^{+}$ cells transitioned into $\mathrm{CD} 43^{+}$hematopoietic cells on day 6 , and $>90 \%$ cells differentiated into $\mathrm{CD} 43^{+}$hematopoietic cells on day 12 . Finally, CD $45^{+}$HPCs were generated from $\sim 60 \%$ of $\mathrm{CD} 43^{+}$cells by day 18 (Figure $7 \mathrm{~B}$ ).

\section{Discussion}

In this study, we developed a novel stepwise strategy for inducing hESC differentiation in a CDM through sequential stages, including PS/early mesoderm induction, HE cell specification, hematopoietic cell emergence and hematopoietic progenitor generation. This strategy recapitulated the main embryonic hematopoietic development
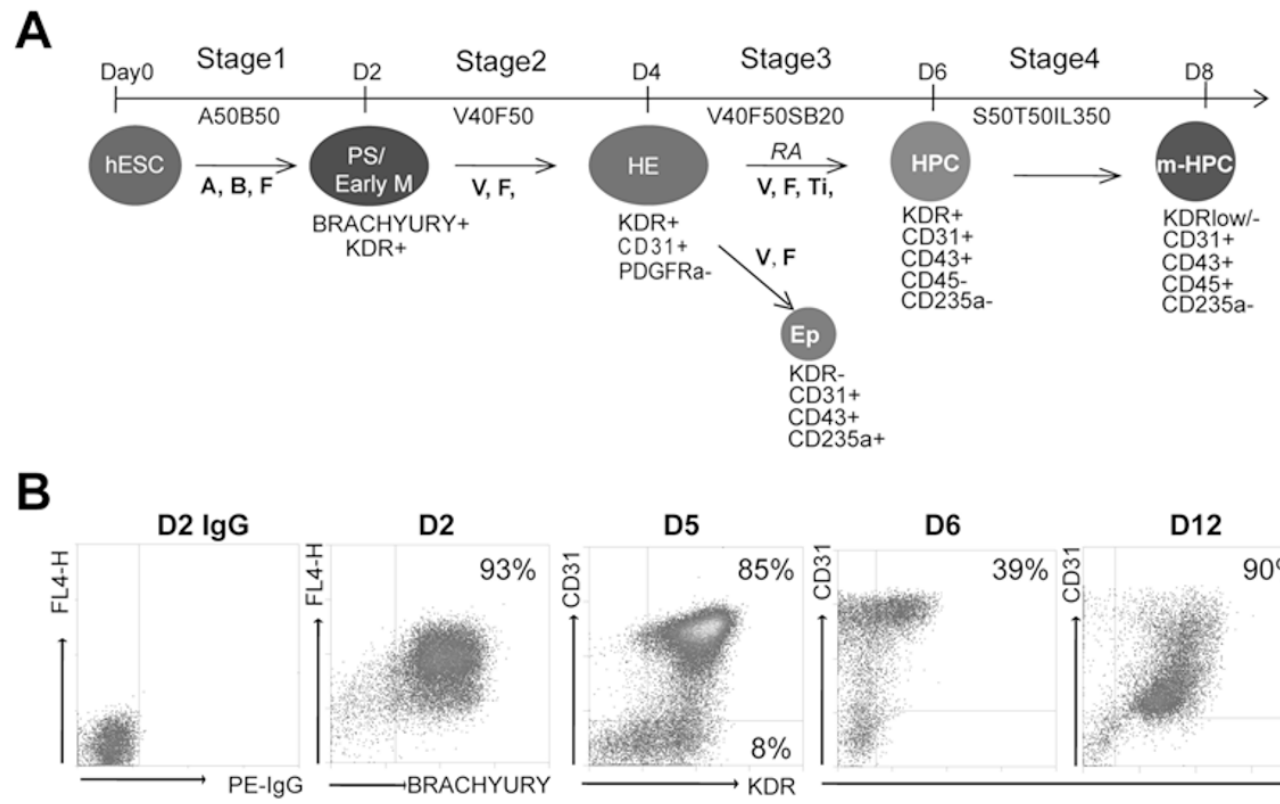

D6

D12

D18

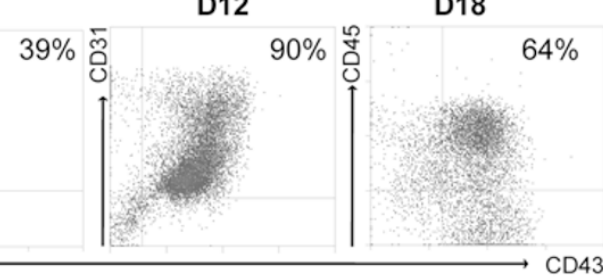

Figure 7 The efficient generation of hematopoietic progenitors from hESCs using a four-step differentiation strategy. (A) The scheme of a well-defined stepwise strategy for differentiation from hESCs. Activin A, BMP4 and bFGF are required to generate primitive streak-like cells and early mesoderm cells at the first stage. VEGF is essential and sufficient to induce HE cells and can further commit HE cells into hematopoietic cells, and bFGF is synergetic with VEGF at the second and third stages. Inhibition of the TGF $\beta$ signal is required for generating hematopoietic cells at the third stage. Hematopoietic cytokines, such as SCF, TPO and IL-3, can further generate CD45 ${ }^{+}$HPCs from CD43 ${ }^{+}$CD235a ${ }^{-}$HPCs. (B) Efficient generation of BRA$\mathrm{CHURY}^{+} / \mathrm{KDR}^{+}$early mesoderm cells, CD $31^{+} \mathrm{HE}$ cells, CD $43^{+}$hematopoietic cells and $\mathrm{CD} 43^{+} \mathrm{CD} 45^{+}$hematopoietic progenitors. Each step was performed according to $\mathbf{A}$. 
stages, as evaluated by determining the sequential onset of expression of BRACHYURY/KDR, CD31, CD43 and CD45. Thus, this strategy provided a reliable system to elucidate the signals regulating early hematopoietic development. Using this stepwise strategy, we identified critical signals regulating the generation of HE cells from hESC-derived early mesoderm cells and the transition from HE cells into HPCs in vitro. The elucidation of these crucial signals regulating early hematopoiesis makes it possible for us to efficiently generate HPCs from hESCs.

Among these differentiation stages, the step of $\mathrm{CD} 43^{+} \mathrm{CD} 45^{-}$hematopoietic cells emerging from $\mathrm{HE}$ cells would be the most critical during embryonic hematopoiesis in vivo and the hematopoietic differentiation in vitro. Recent progress has demonstrated that HSCs are originated directly from HE cells located in the AGM region during the embryogenesis $[25,26,34]$. During the hematopoietic differentiation of $\mathrm{mESCs}$, HE cells have been identified to directly generate $\mathrm{CD} 41^{+}$hematopoietic cells when mESCs are co-cultured with OP9 cells [29]. A study of hESC hematopoietic differentiation has shown that primitive endothelial cells expressing CD31 have hemangioblastic properties and that these CD $31^{+}$ cells further generated $\mathrm{CD} 45^{+}$hematopoietic progenitors [30]. In addition, CD43 has been identified as the first marker expressed in hematopoietic progenitors and has been shown to discriminate hematopoietic cells from endothelial cells during hESC differentiation in vitro [30]. Using a CDM, our study is the first report to recapitulate hematopoietic ontogeny in vitro through PS cell/early mesoderm induction, $\mathrm{HE}$ cell specification, $\mathrm{CD} 43^{+}$hematopoietic emergence and $\mathrm{CD} 43^{+} \mathrm{CD} 45^{+}$hematopoietic progenitor generation (Figure 1A and 1B). Among these steps, the step of $\mathrm{CD} 43^{+}$hematopoietic progenitor emergence from HE cells is probably the most critical point in determining the early hematopoietic fate. Therefore, our established accessible system for defining signals and uncovering new fate-determining factors regulating hematopoietic progenitor emergence will be valuable.

On the basis of the step of generating $\mathrm{CD} 43^{+} \mathrm{HPCs}$ from $\mathrm{HE}$ cells in our defined stepwise differentiation system, we identified that VEGF, bFGF, TGF $\beta$ inhibition and RA signals regulated the process of generating $\mathrm{CD} 43^{+}$cells from $\mathrm{CD} 31^{+}$-enriched HE cells. In our study, VEGF was identified not only as an inducer of CD31 $1^{+}$enriched HE cells from early mesoderm cells but also to commit HE cells into hematopoietic progenitors. VEGF has been reported to play roles in the hematopoietic differentiation of hESCs in the EB system; however, VEGF was added throughout the differentiation process [11]. Our study in a defined system identified that VEGF was essential and sufficient to specify $\mathrm{CD} 31^{+}$-enriched HE cells from the early mesoderm, and also commit these $\mathrm{HE}$ cells into $\mathrm{CD} 43^{+}$hematopoietic progenitors (Figure 2 ). Therefore, our study clearly demonstrates the critical role of VEGF in the specification of HE cells and the generation of hematopoietic progenitors during hESC hematopoietic differentiation.

In this study, we identified TGF $\beta$ as a novel signal regulating the transition of $\mathrm{CD}_{4} 3^{+}$hematopoietic cells from $\mathrm{HE}$ cells. In our differentiation strategy, SB administration from day 4, when HE cells were generated, greatly enhanced the generation of $\mathrm{CD} 43^{+}$hematopoietic progenitors, hematopoietic gene expression and hematopoietic colony formation (Figures 3-5). Significantly, VFSB-induced HPCs had the capacity to survive and proliferate for 1 month of culture and still possessed the multilineage differentiation capacity (Figure 5D, $5 \mathrm{G})$ to generate CFU-E, CFU-G, CFU-M and CFU-GM. Thus, the inhibition of TGF $\beta$ using SB greatly promotes hematopoiesis, particularly enhancing the generation of hematopoietic progenitors from hESC-derived HE cells. These effects probably resulted from the inhibition of endogenous TGF $\beta 1$ expressed by differentiated cells because exogenous TGF $\beta 1$ completely blocked hematopoietic progenitor emergence from HE cells (Figure 4E). It was reported that hematopoietic progenitors were generated through co-culture with AM20.1B4, which secreted TGF $\beta 1$ and TGF $\beta 3$ signals to regulate hematopoietic progenitor generation [3]. The effects of TGF $\beta 1$ in the co-culture system are opposite from the results from our study. This difference could be due to the differences between the co-culture system and CDM. In line with our results, recent studies have shown that the inhibition of TGF $\beta$ using SB greatly enhances the generation of neural cells, hepatocytes and endothelial cells from human pluripotent stem cells, which may result from SB blocking the inhibitory effects of TGF $\beta$ on neural and hepatic differentiation $[35,36]$ and on endothelial expansion $[37$, $38]$.

In our study, we further evaluated the effects of SB on survival and proliferation using PI/Annexin $\mathrm{V}$ and Ki67, respectively (Figure 6). Our results demonstrated that SB did not affect proliferation rates compared with VF (Figure 6D), but decreased the apoptotic rates of human hESC-derived CD $31^{+}$cells and enhanced the gene expression of anti-apoptotic genes, such as $B C L 2$, $M D M 2$ and $B A X$ (Supplementary information, Figure S5). Although SB decreased the $\mathrm{CD} 43^{+} 7-\mathrm{AAD}^{+}$cells, the ratio of this population was low (Figure 6B). Therefore, these results suggested that SB enhanced the generation of HPCs from hESCs, probably through anti-apoptotic effects, and other mechanisms regulating the transition 
of $\mathrm{CD} 43^{+}$cells from $\mathrm{HE}$ cells may remain, which will be investigated in our future studies.

In summary, we have identified signals regulating the generation of HPCs from hESCs and developed a defined stepwise differentiation approach to efficiently produce hematopoietic progenitors from hESCs. This work provides a valuable model to study the signals regulating the generation of HPCs and will facilitate the future use of human pluripotent stem cells in the therapy of blood disorders.

\section{Material and Methods}

\section{Human ES cell culture}

H1 and H9 hES cell lines (Wicell Research Institute, Madison, WI, USA) were expanded on mitomycin C-treated primary mouse embryonic fibroblast cells in hESC culture medium consisting of DMEM/F 12 supplemented with $20 \%$ knockout serum replacement, $1 \mathrm{mM}$ glutamax, $1 \%$ non-essential amino acids, $1 \%$ penicillin/streptomycin, $0.1 \mathrm{mM} \beta$-mercaptoethanol (all from Gibco, Grand Island, NY, USA), and $10 \mathrm{ng} / \mathrm{ml}$ human bFGF (Peprotech, Rocky Hill, NJ, USA) at $37{ }^{\circ} \mathrm{C}$ and $5 \% \mathrm{CO}_{2}$ in a $100 \%$ humidified atmosphere incubator. Cells were split 1:3-1:5 every 5-7 days using $1 \mathrm{mg} / \mathrm{ml}$ dispase (Gibco).

\section{Human ES cell differentiation into hematopoietic cells}

For hematopoietic differentiation, $70 \%-80 \%$ confluent hESCs were treated with $1 \mathrm{mg} / \mathrm{ml}$ dispase (Gibco) for $5 \mathrm{~min}$ in a $37{ }^{\circ} \mathrm{C}$ incubator. Small scraped clumps were then collected and replated into Matrigel-pretreated (1:30 dilution; BD) 12-well or 24-well plates with hESC culture medium. The initial hESC density (1-2 $\times 10^{5} /$ well in 12 -well plate) resulted in a low differentiation efficiency, while the improved density of $\sim 0.5 \times 10^{5}$ cells/well in a 12 -well plate resulted in higher hematopoietic differentiation efficiency. After overnight culture, hESCs were induced for stepwise differentiation under normoxic conditions. First, $50 \mathrm{ng} / \mathrm{ml}$ activin A and $50 \mathrm{ng} / \mathrm{ml} \mathrm{BMP} 4$ or $50 \mathrm{ng} / \mathrm{ml} \mathrm{BMP4}$ and $50 \mathrm{ng} / \mathrm{ml} \mathrm{bFGF}$ were added to the basic CDM of RPMI 1640 (Gibco) supplemented with $1 \mathrm{mM}$ glutamax, $1 \%$ non-essential amino acids, $1 \%$ penicillin/streptomycin and $0.1 \mathrm{mM} \beta$-mercaptoethanol and $1 \%$ insulin-transferrin-selenium (ITS; Gibco). Second, VEGF and bFGF were added in CDM. Other factors tested at this stage are listed in Supplementary information, Table S1. Third, signal factors were added in CDM from days 4-6 as listed in Supplementary information, Table S1. Finally, differentiated cells at day 6 were resuspended in ultra-low attachment 24-well plates (Corning) and were cultured in HCM containing StemPro (Gibco), 1\% penicillin/ streptomycin, $1 \%$ ITS, $1 \mathrm{mM}$ glutamax, $1 \%$ NAA, $1 \%$ penicillin/ streptomycin, 2\% B27 (all from Gibco), 0.1 mM MTG (Sigma), 50 $\mathrm{ng} / \mathrm{ml} \mathrm{SCF}, 50 \mathrm{ng} / \mathrm{ml}$ TPO and $50 \mathrm{ng} / \mathrm{ml} \mathrm{IL3.} \mathrm{SCF,} \mathrm{TPO} \mathrm{and} \mathrm{IL3}$ were purchased from Peprotech. Half of the medium was changed every 2 days.

\section{Flow cytometry}

Cells were trypsinized into single cells using $0.25 \%$ trypsin (Gibco) and resuspended in PBS containing 2\% FBS. The cells were incubated with isotypic antibodies or the indicated antibod- ies for $30 \mathrm{~min}$ at $4{ }^{\circ} \mathrm{C}$. Next, the cells were washed three times with PBS and suspended in $0.4 \mathrm{ml}$ PBS for analysis. A total of $5 \mu \mathrm{l}$ 7-AAD (BD Biosciences, San Jose, CA, USA) was added to each sample, and the samples were incubated for $5 \mathrm{~min}$ before analysis. Flow cytometry analysis was performed using FACS Calibur (BD Biosciences). The data were analyzed using Submit 4.0 (DakoCytomation, Fort Collins, CO, USA). The following antibodies were used: PE-BRACHYURY, APC-KDR, APC-TIE2 and PE-CD105 (R\&D Systems) and PE-mouse IgG1, APC-mouse IgG1, FITCmouse IgG1, PE-CD31, FITC-CD43, PE-CD34, APC-CD34, FITC-CD34, PE-CD45, APC-CD45, PE-PDGFR $\alpha$, APC-C-KIT, APC-TIE2, APC-endoglin and APC-CD235a (BD Biosciences). For intracellular staining of BRACHYURY, the procedure was performed according to the manufacturer's instructions (R\&D Systems).

\section{Fluorescence-activated cell sorting and magnetic-activated cell sorting}

Differentiated cells were dissociated using trypsin (From Gibco), resuspended in PBS with $2 \%$ FBS, filtered through a 40 $\mu \mathrm{m}$ cell strainer (BD Falcon, Franklin Lakes, NJ, USA) and resuspended in $300 \mu \mathrm{l}$ of PBS containing $0.5 \%$ BSA. These cells were incubated with FITC-CD43 and PE-CD31 for 20 min at $4{ }^{\circ} \mathrm{C}$, washed and sorted using a fluorescence-activated cell sorter (MoFlo). Differentiated cells were collected and stained using CD31 micro-beads (Miltenyi Biotec, Auburn, CA, USA) according to the manufacturer's instructions. The cells were suspended in PBS with $0.5 \% \mathrm{BSA}$ and passed through a $\mathrm{MS}^{+}$column (Miltenyi Biotec).

\section{Quantitative PCR}

The total RNA of cultured cells was extracted using TRIzol (Invitrogen), and the total RNA of sorted cells was extracted using a micro-scale RNA isolation kit (RNAqueous-Micro, Ambion, TX, USA). Reverse transcription was performed according to the manufacturer's instructions (Promega, Madison, WI, USA). RNA expression levels were quantified using quantitative RT-PCR (QPCR). Q-PCR was performed using SYBR Green (Invitrogen). RNA levels were normalized using GAPDH as an internal control.

\section{Colony-forming cell assay}

Single cells of the indicated numbers in $0.1 \mathrm{ml}$ IMDM with 2\% FBS were mixed with $1 \mathrm{ml}$ MethoCult $\mathrm{GF}^{+} 4435$ (Stemcell Technologies). The mixture was then transferred to 2 wells of ultra-low attachment 24-well plates (Corning). The cells were incubated at $37{ }^{\circ} \mathrm{C}$ in $5 \% \mathrm{CO}_{2}$ with $100 \%$ humidity for 14 days, and the colonies were counted. Each type of colony was classified according to morphology. Each assay was performed in triplicate.

\section{Apoptosis analysis and proliferation assay}

HESCs were differentiated using 2 days of treatment with activin A + BMP4 and 2 days of treatment with VEGF + bFGF and followed by VEGF + bFGF (VF) or VEGF + bFGF + SB (VFSB). The differentiated cells were trypsinized using trypsin without EDTA at days 5 and 6 and then analyzed using PI- and FITC-Annexin V staining (Xinbosheng Company, Beijing, China). Flow cytometry analysis was performed using FACS Calibur (BD Biosciences). The data were analyzed using Submit 4.0 (DakoCytomation). To examine apoptotic cells among $\mathrm{CD}^{2} 3^{+}$cells, we costained VF- and VFSB-treated differentiated cells with 7-AAD (BD 
Falcon). Flow cytometry analysis of CD43/7-AAD was performed using FACS Calibur (BD Biosciences), and the data were analyzed using Submit 4.0 (DakoCytomation).

To test the proliferation rates of differentiated cells, cells differentiated at day 5 and day 6 were collected and stained using a PECD31 antibody (BD) and a rabbit anti-human Ki67 primary antibody (Santa Cruz), followed by a FITC-conjugated mouse antirabbit secondary antibody (Santa Cruz). Flow cytometry analysis was performed using FACS Calibur (BD Biosciences). The data were analyzed using Submit 4.0 (DakoCytomation).

\section{Acknowledgments}

We thank Yizhe Zhang, Haisong Liu, Yan Shi, Hongxia Lv, Ting Liu and other colleagues in our laboratory for providing technical assistance and discussions in the preparation of this manuscript. This work was supported by grants from the Ministry of Science and Technology (2011DFA30730), the 111 project, the National Basic Research Program of China (973 program, 2011CB964800 and 2010CB945204) and the Bill \& Melinda Gates Foundation (37871 to H Deng). This work was supported by a China Postdoctoral Science Foundation (20100319 to C Wang).

\section{References}

1 Chadwick K, Wang L, Li L, et al. Cytokines and BMP-4 promote hematopoietic differentiation of human embryonic stem cells. Blood 2003; 102:906-915.

2 Ledran $\mathrm{MH}$, Krassowska A, Armstrong L, et al. Efficient hematopoietic differentiation of human embryonic stem cells on stromal cells derived from hematopoietic niches. Cell Stem Cell 2008; 3:85-98.

3 Tian X, Kaufman DS. Hematopoietic development of human embryonic stem cells in culture. Methods Mol Med 2005; 105:425-436.

4 Vodyanik MA, Bork JA, Thomson JA, Slukvin II. Human embryonic stem cell-derived CD34+ cells: efficient production in the coculture with OP9 stromal cells and analysis of lymphohematopoietic potential. Blood 2005; 105:617-626.

5 Kennedy M, D'Souza SL, Lynch-Kattman M, Schwantz S, Keller G. Development of the hemangioblast defines the onset of hematopoiesis in human ES cell differentiation cultures. Blood 2007; 109:2679-2687.

6 Grigoriadis AE, Kennedy M, Bozec A, et al. Directed differentiation of hematopoietic precursors and functional osteoclasts from human ES and iPS cells. Blood 2010; 115:27692776.

7 Choi KD, Yu J, Smuga-Otto K, et al. Hematopoietic and endothelial differentiation of human induced pluripotent stem cells. Stem Cells 2009; 27:559-567.

8 Nostro MC, Cheng X, Keller GM, Gadue P. Wnt, activin, and BMP signaling regulate distinct stages in the developmental pathway from embryonic stem cells to blood. Cell Stem Cell 2008; 2:60-71.

9 Pearson S, Sroczynska P, Lacaud G, Kouskoff V. The stepwise specification of embryonic stem cells to hematopoietic fate is driven by sequential exposure to Bmp4, activin A, bFGF and VEGF. Development 2008; 135:1525-1535.

10 Park C, Afrikanova I, Chung YS, et al. A hierarchical order of factors in the generation of FLK1- and SCL-expressing hematopoietic and endothelial progenitors from embryonic stem cells. Development 2004; 131:2749-2762.

11 Pick M, Azzola L, Mossman A, Stanley EG, Elefanty AG. Differentiation of human embryonic stem cells in serum-free medium reveals distinct roles for bone morphogenetic protein 4, vascular endothelial growth factor, stem cell factor, and fibroblast growth factor 2 in hematopoiesis. Stem Cells 2007; 25:2206-2214.

12 Mikkola HK, Orkin SH. The journey of developing hematopoietic stem cells. Development 2006; 133:3733-3744.

13 Dzierzak E, Speck NA. Of lineage and legacy: the development of mammalian hematopoietic stem cells. Nat Immunol 2008; 9:129-136.

14 Tam PP, Beddington RS. The formation of mesodermal tissues in the mouse embryo during gastrulation and early organogenesis. Development 1987; 99:109-126.

15 Lawson KA, Meneses JJ, Pedersen RA. Clonal analysis of epiblast fate during germ layer formation in the mouse embryo. Development 1991; 113:891-911.

16 Kinder SJ, Tsang TE, Quinlan GA, Hadjantonakis AK, Nagy A, Tam PP. The orderly allocation of mesodermal cells to the extraembryonic structures and the anteroposterior axis during gastrulation of the mouse embryo. Development 1999; 126:4691-4701.

17 Yoder MC, Hiatt K, Dutt P, Mukherjee P, Bodine DM, Orlic D. Characterization of definitive lymphohematopoietic stem cells in the day 9 murine yolk sac. Immunity 1997; 7:335-344.

18 Palis J, Robertson S, Kennedy M, Wall C, Keller G. Development of erythroid and myeloid progenitors in the yolk sac and embryo proper of the mouse. Development 1999; 126:50735084.

19 Medvinsky A, Dzierzak E. Definitive hematopoiesis is autonomously initiated by the AGM region. Cell 1996; 86:897906.

20 Cumano A, Ferraz JC, Klaine M, Di Santo JP, Godin I. Intraembryonic, but not yolk sac hematopoietic precursors, isolated before circulation, provide long-term multilineage reconstitution. Immunity 2001; 15:477-485.

21 Ottersbach K, Dzierzak E. The murine placenta contains hematopoietic stem cells within the vascular labyrinth region. Dev Cell 2005; 8:377-387.

22 Gekas C, Dieterlen-Lievre F, Orkin SH, Mikkola HK. The placenta is a niche for hematopoietic stem cells. Dev Cell 2005; 8:365-375.

23 Robin C, Bollerot K, Mendes S, et al. Human placenta is a potent hematopoietic niche containing hematopoietic stem and progenitor cells throughout development. Cell Stem Cell 2009; 5:385-395.

24 Chen MJ, Yokomizo T, Zeigler BM, Dzierzak E, Speck NA. Runx1 is required for the endothelial to haematopoietic cell transition but not thereafter. Nature 2009; 457:887-891.

25 Kissa K, Herbomel P. Blood stem cells emerge from aortic endothelium by a novel type of cell transition. Nature 2010; 464:112-115.

26 Bertrand JY, Chi NC, Santoso B, Teng S, Stainier DY, Traver D. Haematopoietic stem cells derive directly from aortic endothelium during development. Nature 2010; 464:108-111.

27 Peault B, Tavian M. Hematopoietic stem cell emergence in the 
human embryo and fetus. Ann N Y Acad Sci 2003; 996:132140.

28 Oberlin E, Tavian M, Blazsek I, Peault B. Blood-forming potential of vascular endothelium in the human embryo. Development 2002; 129:4147-4157.

29 Eilken HM, Nishikawa S, Schroeder T. Continuous single-cell imaging of blood generation from haemogenic endothelium. Nature 2009; 457:896-900.

30 Wang L, Li L, Shojaei F, et al. Endothelial and hematopoietic cell fate of human embryonic stem cells originates from primitive endothelium with hemangioblastic properties. Immunity 2004; 21:31-41.

31 Vodyanik MA, Thomson JA, Slukvin II. Leukosialin (CD43) defines hematopoietic progenitors in human embryonic stem cell differentiation cultures. Blood 2006; 108:2095-2105.

32 Zhang P, Li J, Tan Z, et al. Short-term BMP-4 treatment initiates mesoderm induction in human embryonic stem cells. Blood 2008; 111:1933-1941.

33 Yu C, Liu Y, Miao Z, et al. Retinoic acid enhances the generation of hematopoietic progenitors from human embryonic stem cell-derived hemato-vascular precursors. Blood 2010;
116:4786-4794.

34 Boisset JC, van Cappellen W, Andrieu-Soler C, Galjart N, Dzierzak E, Robin C. In vivo imaging of haematopoietic cells emerging from the mouse aortic endothelium. Nature 2010; 464:116-120.

35 Chambers SM, Fasano CA, Papapetrou EP, Tomishima M, Sadelain M, Studer L. Highly efficient neural conversion of human ES and iPS cells by dual inhibition of SMAD signaling. Nat Biotechnol 2009; 27:275-280.

36 Touboul T, Hannan NR, Corbineau S, et al. Generation of functional hepatocytes from human embryonic stem cells under chemically defined conditions that recapitulate liver development. Hepatology 2010; 51:1754-1765.

37 James D, Nam HS, Seandel M, et al. Expansion and maintenance of human embryonic stem cell-derived endothelial cells by TGFbeta inhibition is Id1 dependent. Nat Biotechnol 2010; 28:161-166.

38 Takehara K, LeRoy EC, Grotendorst GR. TGF-beta inhibition of endothelial cell proliferation: alteration of EGF binding and EGF-induced growth-regulatory (competence) gene expression. Cell 1987; 49:415-422.

(Supplementary information is linked to the online version of the paper on the Cell Research website.) 